Dear Author,

Please, note that changes made to the HTML content will be added to the article before publication, but are not reflected in this PDF.

Note also that this file should not be used for submitting corrections. 


\title{
Food law compliance in developed and developing countries: Comparing school kitchens in Lincolnshire-UK and Ashanti Region of
} Q10 Ghana

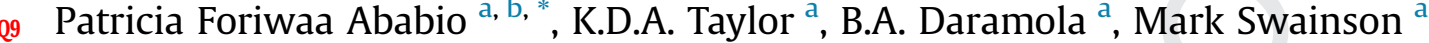 \\ 01 a National Center for Food Manufacturing, College of Sciences, University of Lincoln, UK \\ ${ }^{\mathrm{b}}$ Department of Hospitality and Tourism Education, Faculty for Vocational Education, University of Education, Winneba, Kumasi Campus, Ghana
}

\section{A R T I C L E I N F O}

\section{Article history:}

Received 3 December 2015

Received in revised form

10 March 2016

Accepted 15 March 2016

Available online $\mathrm{xxx}$

\section{Keywords:}

Food law compliance

Food hygiene and safety

Kitchen staff

School meals

\begin{abstract}
A B S T R A C T
The demands and requirements of Food Laws remain the same internationally as food hazards present the same risks to individuals including school going age children and adolescents, however different nations with different economic and developmental issues differ in the level of importance attached to Food Law requirements. A questionnaire to assess good hygiene practices in schools in Lincolnshire-UK and Ashanti Region of Ghana to compare compliance with training requirement in Food Laws was administered in 10 Lincolnshire and 45 Ashanti Region secondary schools. Whilst the demands on good hygiene practices remain stringently upheld in schools in the United Kingdom the same could not be said of Ghana. Although 60\% of schools in Ashanti Region of Ghana fed between 1000 and 3000 students thrice a day, there was no evidence of food safety management system in all the schools. Staff food and personal hygiene practices including, temperature control, hand washing, avoidance of self-adornments, infectious disease control were substandard. A mandatory requirement by Food Laws in both countries for persons in supervisory position was not stringently complied with as $31 \%$ of kitchen matrons reported not to have hygiene qualification in the Ashanti Region of Ghana and 82\% of 180 staff sampled had never received hygiene training. The absence of mandatory hygiene training for all food handlers, kitchen managers/matrons with requisite hygiene knowledge and qualification and rigorous enforcement of these remain challenges to good hygiene practices and Food Legislation in Ghana in addition to suitable facilities. The development of food hygiene training programmes towards mandatory certification at different levels of responsibility for the industry is required to help curb the identified challenges.
\end{abstract}

(C) 2016 Published by Elsevier Ltd.

http://dx.doi.org/10.1016/j.foodcont.2016.03.023

0956-7135/@ 2016 Published by Elsevier Ltd. 
is fundamentally comparable internationally and legally binding. Food laws essentially require food prepared for sale to be safe and not injurious to health, to be prepared under hygienic conditions by people with the necessary training and with good hygiene practice. The 1990 Food Safety Act of UK (Food Standard Agency, 2013), the Public Health Act of Ghana, Act 851 (Food and Drugs Authority, 2012) and the 1992 Food and Drugs Law, PNDCL 305B of Ghana (Food and Drugs Authority, 1992) stress on the illegality of the sale of unwholesome food, food that has been adulterated, food prepared in unsanitary conditions and the need for supervision by an authorised person or persons with the technical know-how. Thus staff training for instance is a legal requirement and should commensurate with employee responsibilities. Good hygiene practices also positively affect the wholesomeness of food and conditions under which food is prepared. The universality of Food Law is due to the fact that food risks are the same and also food travels globally hence a risk in one country becomes a burden for all. Compliance to Food Law and good industrial practices for instance Good Hygiene Practices (GHP) in food service establishments is limited by several factors including finance, lack of resources and technical knowledge, lack of motivation and interest from management, absence of effective enforcement agencies (Panisello et al., 2000; Taylor, 2001 and Ababio \& Lovatt, 2015) and consumer pressure groups. The research investigated food hygiene conditions and practices in secondary school kitchens in Lincolnshire-UK and the Ashanti Region of Ghana in compliance to Food Law requirements. Whilst in the UK, GHP is a legal requirement for the food industry and Hazard Analysis and Critical Control Point (HACCP) moved from recommendation status to Law in 2006 by EU Council Regulation 852/2004 (European Union, 2004) requiring food business to implement a system based on HACCP principles, the same could not be said of Ghana. A recent study by Ababio et al., (2013) indicated limited established and documented GHPs in the indigenous food service and processing industries in Ghana. HACCP was also not available in most local food establishments of which Johnson et al., (2008) recommended for the improvement of food safety in the country. Food poisoning occur in schools in both the developed and developing countries (Ababio \& Lovatt, 2015; Malm et al., 2015; Marzano and Balzaratti, 2013; Rodriquez Caturla, 2012; Gupta \& Gupta, 2009; Meldrum, Mannion, \& Garside, 2009; Santana, Almeida, Ferreira, \& Almeida, 2009; Sneed \& Henroid, 2007 and Daniels et al., 2002) and the Ministry of Health in Ghana reported of 1348 children suffering from food poisoning in the year 2007 in the capital city alone (Ministry of Health, 2007) however the affected schools in Ghana were reported to have poor food storage facilities and lacked protocols to prevent reoccurrence (Malm et al., 2015; Gupta \& Gupta, 2009). In developed countries causes of foodborne illness are often traced and corrective measures taken by management (Meldrum et al., 2009; Daniels et al., 2002) to prevent reoccurrence as part of standard operating procedures. The research investigated the availability of good hygiene practices including staff training in schools in the Lincoln-UK and Ashanti Region of Ghana in compliance to Food Law requirements.

\section{Methodology}

The research took the form of a survey as part of an attempt to compare hygiene practices of kitchen staff in Senior High Schools (SHS) in Ghana to school kitchens in a developed country with standardised systems towards the introduction of acceptable international standards of operation. Separate questionnaires were developed for school kitchen managers or matrons and kitchen staff. An audit checklist for visual investigation on hygiene standards was also done with the help of an adopted checklist from Santana et al. (2009) in Brazil. Permission to visit both schools in
Lincolnshire and Ghana were sought through the Dean of the National Centre for Food Manufacturing to the matrons in Lincolnshire schools and through the Ashanti Region Education Director to the Heads of Senior Secondary Schools in the Region. Ten academy schools were visited in Lincolnshire out of which 10 matrons and 12 kitchen staff completed questionnaires designed to solicit for information on hygiene standards, awareness and practices and training availability in the schools. In the Ashanti Region of Ghana, visit to the schools begun from the Kumasi Metropolis (the capital) and to surrounding towns and villages in the Region with the aim of visiting all the schools. The visits ended when the schools vacated. Fifty eight (58) public Senior High Schools (SHS) were visited out of 86 of which 45 (52\%) were available for the exercise. Forty five (45) kitchen matrons and 180 kitchen staff (4 per school) completed questionnaire on food hygiene standards, food hygiene awareness and practice. and training availability. Matrons/managers questionnaire included questions on educational background and hygiene qualification, operational Food Safety Management System availability and Managers willingness to establish one if absent, and factors affecting their decision. Kitchen staff questionnaire included process and personal hygiene awareness and practices that affect food safety, health screening before employment and training availability and whether they were happy to receive training if available.

\subsection{Rational for the choice of sample}

Lincolnshire was chosen due to its proximity to the researcher's University whilst Ashanti Region of Ghana was chosen as the highest populated region among the ten regions in the country (Ghana Statistical Service, 2012) holding 17.4\% of the 493 public SHSs in the country and admitted $44.4 \%$ of the total students intake into SHSs in the country in 2009 (Ministry of Education, 2009). Ghanaian population in the year 2010 as reported by the Ghana Statistical Service (2012) was $40.1 \%$ of the population of the UK (Table 1) in the same year. Ghanaian's total number of foodborne illness and related deaths annually exceed that of UK and money spent during hospitalisation and treatment in the UK however is far higher than that reported in Ghana. The economic cost of foodborne illness estimates in the UK are based on lost earnings, cost from pain, suffering and others (Food Standard Agency, 2011; Abelson, Forbes, \& Hall, 2006) whilst in Ghana cost to productivity is often mentioned (Food and Drugs Authority, 2008). Law enforcement and surveillance of the food service industry prevailing in the UK that tend to protect consumers could be adopted in Ghana towards consumer safety and longer life expectancy.

\subsection{Ethical consent}

Participants from schools in Ashanti Region of Ghana were given a consent form to sign on their approval and acknowledgement of the voluntary nature of their participation and the fact that their identity will not be disclosed either during or after the research. They were assured that they had the right to pull out of the study at any point if they were not happy to continue with the researcher. An agreement to the above was signed by the respondents.

\subsection{Statistical analysis}

Qualitative tools on SPSS Version 21 were used to develop frequency tables and cross tabulations of variables to find the relationship between the two countries with different enforcement backgrounds.

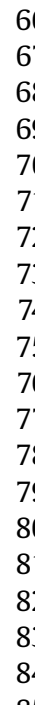


Table 1

Foodborne diseases and effect in UK and Ghana according to literature.

\begin{tabular}{|c|c|c|}
\hline Statistics & UK & Ghana \\
\hline 2010 total population & 62,300,000 (Office of National Statistics, UK, 2013) & 25,000,000 (Ghana Statistical Service, 2012) \\
\hline $\begin{array}{l}\text { Annual food poisoning incidence } \\
\text { estimates }\end{array}$ & $\begin{array}{l}\text { 1,000, } 000 \text { cases of foodborne illness with }>500,000 \text { from known pathogens } \\
\text { (Food Standard Agency, 2011, 2014) }\end{array}$ & $\begin{array}{l}625,000^{a} \text { people annually (Ministry of Food and } \\
\text { Agriculture/World Bank, 2007) }\end{array}$ \\
\hline Annual Hospitalisation & 20,000 people receive treatment (Food Standard Agency, 2011) & $\begin{array}{l}297,104 \text { people hospitalised annually (Food and Drugs } \\
\text { Authority, 2008) }\end{array}$ \\
\hline $\begin{array}{l}\text { Annual death rate due to food } \\
\text { related illnesses }\end{array}$ & 500 deaths annually (Food Standard Agency, 2011) & $\begin{array}{l}\text { 90,692 deaths annually (Food and Drugs Authority, } \\
\text { 2008) }\end{array}$ \\
\hline Annual Cost of foodborne illness & 1.5 billion GBPs (Food Standard Agency, 2011) & $\begin{array}{l}69 \text { million US } \$ / 44.2 \text { million } \mathrm{GBP}^{\mathrm{b}} \text { (Food and Drugs } \\
\text { Authority, 2008) }\end{array}$ \\
\hline 2010 Life expectancy & 80.4 years (World Bank 2016) & 60.6 years (World Bank, 2016) \\
\hline
\end{tabular}

${ }^{a}$ Based on 1 in every 4 Ghanaian suffering from foodborne illness annually reported by MOFA/FAO (2007) and 2010 population.

b Based on 2010 Pound to Dollar rate.

\section{Results and discussion}

\subsection{School demographics in Lincolnshire and Ashanti Region of Ghana}

Food Safety Management Systems (FSMS) take time to be established and to be in smooth operation and majority of the schools both in Lincolnshire and Ashanti Region were above 30 years hence could be in position to improve operational standards. With EU legislation for food establishments to operate with HACCP principles in place in the year 2006 (European Union, 2004), all the schools visited in Lincolnshire had some form of food safety management system in operation within 9 years of the Law being passed. The same could not be said of Ashanti Region of Ghana where there was no evidence of food safety management system in any of the schools visited (Table 2). This could be due to absence of legislative requirement as indicated by my personal communication with Food Standard Authority personnel in the year 2013 (Food Standard Agency, 2013), lack of rigorous surveillance (DwumfourAsare, 2015), an illusion of safety due to low reporting culture (Panisello et al., 2000) and lack of technical knowledge and resources (Taylor, 2001).

Institutional food establishments are noted to serve higher number of customers per day as compared to commercial settings. This is evidenced in boarding schools where communal type of feeding exist and students mostly depend on feeding programmes provided by their schools (Afoakwa, 2005). Ashanti Region had 60\% of the schools feeding between 1000 and $>2000$ students per meal. Thus a minimum of 3000-6000 plates per day in these schools in the absence of FSMS. This was different from Lincolnshire where all the schools had established HACCP Principles applied systems and handled a significantly lesser ( $p \leq 0.05$ ) number of students (maximum 1000). In communal style of feeding with larger mouths to feed, food poisoning incidence could affect hundreds at a time thus calling food establishments and the legislature in Ghana to put more emphases on the Food Laws and acceptable industrial practices. Daniels et al. (2002) in the US reported that between 1993 and 1997, more than 600 foodborne outbreaks in schools resulted in 50,000 illnesses and 1500 hospitalisations and this could happen in any school without appropriate control measures in place. Food industries in Ghana as a Codex member country have the obligation to operate according to the existing international code of practice. With regards to meal temperature, both Lincolnshire $(81 \%)$ and Ashanti Region schools (67\%) reported to provide a combination of hot and cold meals. Chilling was not practiced in the Ashanti Region schools where freezing storage was paramount. There were however some low risk products like 'kenkey', 'gari' and bread which were stored at ambient temperature and served. These might have been considered as cold preserved food which technically were not. There was the need for cooking time and temperature monitoring as none of the schools in Ashanti Region had temperature monitoring or storage devices like food temperature probes, thermos like containers or Bain Marie for keeping cooked food hot. Food after preparation were kept in cooking pots until service and kept on cooking tripod (locally made cookers) or gas stoves with fire quenched to avoid burning and utility cost. This supports Malm et al. (2015) who reported of poor storage facilities and absence of protocols to prevent food poisoning incidences in affected

Table 2

Schools demographics in Lincolnshire-UK and Ashanti Region of Ghana reported in percentages.

\begin{tabular}{|c|c|c|c|c|}
\hline Variables & & Lincolnshire & Ashanti region & Chi square \\
\hline Schools visited & & 18.18 & 81.82 & \\
\hline \multirow[t]{5}{*}{ Period of existence (years) } & $1-10$ & 1.82 & 7.27 & \\
\hline & $11-20$ & 3.64 & 12.73 & \\
\hline & $21-30$ & 1.82 & 16.36 & \\
\hline & $31-40$ & 0.00 & 5.45 & \\
\hline & $>40$ & 10.91 & 40.00 & \\
\hline \multirow[t]{2}{*}{ Type of kitchen } & Centralised & 1.82 & 0.00 & \\
\hline & Onsite & 16.36 & 81.82 & \\
\hline \multirow[t]{2}{*}{ Types of meals provided } & Hot meals & 1.82 & 27.27 & \\
\hline & Combination of hot and cold & 16.36 & 54.55 & \\
\hline \multirow[t]{4}{*}{ Students served per meal } & $1-500$ & 9.09 & 14.55 & $11.909(0.008)$ \\
\hline & $501-1000$ & 9.09 & 18.18 & \\
\hline & $1001-2000$ & 0.00 & 30.91 & \\
\hline & $>2000$ & 0.00 & 18.18 & \\
\hline \multirow[t]{2}{*}{ Availability of Food safety management system } & Yes & 18.18 & 0.00 & \\
\hline & No & 0.00 & 81.82 & \\
\hline
\end{tabular}

Data on 45 secondary schools from Ashanti Region of Ghana and 10 from Lincolnshire-UK. 
Ghanaian schools in Accra the capital city. This was contrary to the UK condition where all schools had temperature monitoring devices and equipment. Poor food storage temperatures and holding times have been implicated as practices that cause high foodborne disease outbreaks and in a US survey on food poisoning in schools, Daniels et al. (2002) reported that $81 \%$ of 290 outbreaks were due to improper food storage and holding temperatures. Food holding temperatures and time for both hot meals and cold preserves required standardisation in Ghana.

\subsection{Kitchen staff hygiene requirement and food law}

Females were predominantly the gender across Lincolnshire (100\%) and Ashanti region (93\%) school kitchen staff with ages ranging from 19 to 60 years with most staff within the ages of 30-59. Highest form of formal education of kitchen staff (none managers) was basic education in Ashanti Region whilst that of Lincolnshire was secondary education, supporting Ababio and Lovatt (2015). There were still some staff (10\%) with no formal education in the Ghanaian schools which has a detrimental effect on good hygiene practices. Cooking and feeding people seem to be seen as an occupation that does not require a higher form of education, notwithstanding it is a legal requirement that employees are given hygiene training once they are employed and this should commensurate with their roles and responsibilities. In the 1990 Food Safety Act of UK (Food Standards Agency, 2013) under Part II of the Main Provisions there is a requirement for food hygiene training. Codex Alimentarius (WHO/FAO, 2009) equally require the training of kitchen staff and this is applicable to the food industries in Ghana as a Codex member country, however $90 \%$ of kitchen staff in Ghana reported not to have had any form of hygiene training since they started work confirming poor training culture in Ghanaian food establishments (Ababio et al., 2013). In an Indian school gastroenteritis outbreak case affecting 116 students with a median age of 15-20 years, Gupta and Gupta (2009) reported that food handlers and their cooking conditions were unhygienic. They recommended educating the staff and students on good hygiene practices. All staff in Lincolnshire reported on the affirmative with the exception of one on having had training. This exception could be a casual staff from an agency or a new recruit who had not yet been trained, questioning the kind of training given during staff induction as an employment procedure for food handling. All staff from Lincolnshire and 97\% from Ashanti Region were happy to receive routine hygiene training. The management of infectious disease in the food industry is equally an important hygiene practice to ensure safety of consumers and colleagues at work as there is the potential for outbreaks to occur under operational constrains. Chapter VIII on Personal Hygiene, Annex II of Regulation (EC) 852/ 2004 (European Union, 2004) indicates that no person suffering from or being a carrier of a foodborne disease or afflicted with infected wounds, skin infection, sores or diarrhoea should be permitted to handle food or enter any food handling area in any capacity if there is a likelihood of direct or indirect contamination. This led to food establishments demanding pre-employment medical examination and infected staff usually being excluded for $48 \mathrm{~h}$ after symptoms stopped and once treatment had ceased and the person was deemed fit to resume food handling duties. More than half (59\%) of the kitchen staff in Ashanti Region reported of providing medical clearance as part of their pre-employment demands. On the contrary only one staff from Lincolnshire reported on the affirmative to this. Routine screening was however in both areas indicating compliance to this rule. Documentation on this was however scarcely available in Ghana. Legally, the onus is on food managers to ensure that personnel are healthy to handle food and will not present risk to consumers.

\subsection{Staff hygiene practices and food law}

Infectious disease management in Ashanti Region was less standardised as $27 \%$ of the staff reported they were unlikely or most unlikely to report infections symptoms including diarrhoea and vomiting to their managers but did self-medication and returned to work. Another 30\% reported they were not likely or certainly not being given time off to recover from foodborne disease symptoms (Table 3). Thus the $48 \mathrm{~h}$ rule was not applied here. Between 1973 and 1997, over 600 foodborne outbreaks occurred in schools in the US causing 50,000 illnesses with 1500 hospitalisations and $57 \%$ of the cases were attributed to contamination by sick kitchen staff or staff hygiene practices leading to the recommendation for improved food safety measures, staff training and sick leave with pay policies (Daniels et al., 2002). The absence of safety policies such as these is a food safety risk as infected staff could contaminate food and cause a wide spread of infection among students and colleagues. Sumner et al. (2011) reported of a similar experience in the US where some staff reported to report to work with diarrhoea and vomiting symptoms due to absence of policies for staff to absent themselves when sick. This was different in Lincolnshire where all staff reported they most likely will report possible infections and were given or would be given some time off work to recover and avoid possible food contamination by their matrons. Codex Alimentarius Basic Hygiene Text (WHO/FAO, 2009) Section 7.2 equally recommends possible exclusion from food handling with persons suffering from jaundice, diarrhoea, vomiting, fever, sore throat with fever, visible infected skin lesions and discharges from the ear, eye and nose. Hand washing, another good hygiene practice for all food handlers and a major and inexpensive means of preventing transmission of food borne disease (WHO, 2012) was under practiced in the Ashanti Region schools. Whilst all Lincolnshire staff were sure to wash their hands before food preparation and after visiting the toilet, 15\% from Ashanti Region were not likely to wash their hands before food preparation and another $5 \%$ were not likely to wash their hands after visiting the toilet. The absence of hygiene training had an effect on staff awareness of good personal hygiene. Most toilets facilities did not also have readily available wash basins, readily available water and toiletries for staff use during auditing, thus possible management negligence and or economic conditions also affected staff hygiene practices. This was significantly different from Lincolnshire schools where all staff were trained and hand washing was a procedure staff were trained to follow. Hand washing basins with readily available detergents and driers were equally available for staff, thus aiding the practice. The removal of jewellery during food preparation and service to avoid the risk of both physical and microbiological contamination as directed by Codex Alimentarius Section 7.3 on Personal cleanliness (WHO/FAO, 2009) was under practiced in Ashanti Region.

This is a recommended international code of practice for all food handlers and unlike Lincolnshire, 23\% of staff in Ashanti Region were not likely or most unlikely to remove their jewellery during food preparation and service. This supports Rheinlander et al. (2008) who reported that aesthetic values including adorning of self by food handlers was a measure of cleanliness in Ghana, neglecting good hygiene practices like kitchen cleanliness and hand washing. Although most schools (77\%) in Ashanti Region had uniforms for their kitchen staff, cleanliness of it by washing them daily after work was not possible. Twenty three percent (23\%) of the staff reported they were not likely to wash their uniforms on a daily basis. Some reported of having only one uniform and couldn't wash it daily, others commented on the lack of provision of detergents by school management for this purpose. People engaged in food handling activities are cautioned to refrain from behaviour that could contaminate food, these include smoking, spitting, chewing 
Table 3

Kitchen staff hygiene practises in Lincolnshire and Ashanti Region of Ghana reported in percentages.

\begin{tabular}{|c|c|c|c|c|c|c|}
\hline \multirow[t]{2}{*}{ Schools } & \multicolumn{5}{|c|}{ Staff hygiene practices } & \multirow[t]{2}{*}{ Chi square } \\
\hline & Most likely & Likely & Don't know & Unlikely & Most unlikely & \\
\hline & \multicolumn{6}{|c|}{ I report to my manager when I have diarrhoea or other infectious disease } \\
\hline Lincolnshire & 6.25 & 0.00 & 0.00 & 0.00 & 0.00 & $25.600(0.001)$ \\
\hline \multirow[t]{2}{*}{ Ashanti Region } & 27.08 & 38.54 & 6.25 & 16.15 & 5.73 & \\
\hline & \multicolumn{6}{|c|}{ My manager gives me time off until $48 \mathrm{~h}$ after diarrhoea is cleared } \\
\hline Lincolnshire & 6.25 & 0.00 & 0.00 & 0.00 & 0.00 & $25.600(0.001)$ \\
\hline \multirow[t]{2}{*}{ Ashanti Region } & 27.08 & 30.21 & 11.98 & 21.35 & 3.13 & \\
\hline & \multicolumn{6}{|c|}{ I always wash my hands before starting work } \\
\hline Lincolnshire & 6.25 & 0.00 & 0.00 & 0.00 & 0.00 & $14.553(0.006)$ \\
\hline \multirow[t]{2}{*}{ Ashanti Region } & 50.52 & 30.20 & 0.00 & 11.98 & 0.52 & \\
\hline & \multicolumn{6}{|c|}{ I always wash my hands after using the toilet } \\
\hline Lincolnshire & 6.25 & 0.00 & 0.00 & 0.00 & 0.00 & $10.831(0.002)$ \\
\hline \multirow[t]{2}{*}{ Ashanti Region } & 47.92 & 41.15 & 0.52 & 4.17 & 0.00 & \\
\hline & \multicolumn{6}{|c|}{ I remove all my unapproved jewellery before work } \\
\hline Lincolnshire & 5.73 & 0.52 & 0.00 & 0.00 & 0.00 & $12.962(0.005)$ \\
\hline \multirow[t]{2}{*}{ Ghana } & 36.46 & 35.42 & 0.00 & 17.19 & 4.69 & \\
\hline & \multicolumn{6}{|c|}{ Protective clothing are cleaned on a daily basis } \\
\hline Lincoln & 6.25 & 0.00 & 0.00 & 0.00 & 0.00 & $12.800(0.012)$ \\
\hline \multirow[t]{2}{*}{ Ashanti Region } & 43.75 & 28.13 & 0.52 & 19.27 & 2.08 & \\
\hline & \multicolumn{6}{|c|}{ I do eat whilst working } \\
\hline Lincolnshire & 0.00 & 0.00 & 0.52 & 1.04 & 4.69 & $14.533(0.006)$ \\
\hline Ashanti Region & 5.21 & 9.38 & 1.04 & 48.44 & 29.69 & \\
\hline
\end{tabular}

Data on 180 kitchen staff from Ashanti Region and 12 kitchen staff from Lincolnshire.

or eating, sneezing and coughing over unprotected food (WHO/ FAO, 2009). Whilst most staff in Lincolnshire (92\%) and Ashanti Region (83\%) were most unlikely or unlikely to eat during meal preparation $15.6 \%$ from Ghana were most likely or likely to eat during meal preparation. This was possibly due to lack of training and awareness of possible contamination of food through this practice.

\subsection{Kitchen managers/Matron's food hygiene standards and Food Law}

Both the 1990 Food Safety Act of UK (Food Standards Agency, 2013) and the 2012 Public Health Act of Ghana (Food and Drugs Authority, 2012) require persons in supervisory position to have requisite knowledge in food safety and hygiene to ensure that food prepared for human consumption is not rendered injurious to health. In the UK it is a legal requirement that food establishments operate based on the principles of HACCP. Matrons from both regions were predominantly females. The highest number of matrons in Lincolnshire were Secondary School leavers whilst a higher percentage of matrons from Ghana had City and Guilds certificate. Whilst all matrons from Lincolnshire had hygiene qualification, 31\% of matrons from Ashanti Region had no hygiene qualification despite working for up to 20 years in the food industry.

This was contrary to the legislation provision and required enforcement. This directly or indirectly affected other forms of good hygiene practices in the school kitchens including cleaning, food storage temperature and staff personal hygiene. FSMS including Safer Food Better Business and other forms of HACCP applications were in place in Lincolnshire schools but absent in all schools in Ghana. This was still not a legal requirement in Ghana unlike the UK although over $86 \%$ of matrons in the Ashanti Region would be happy to have a Food Safety Management Systems in place (Table 4). Those who reported lack of interest in establishing HACCP in schools cited having been operating safely so far as a reason thus supporting Taylor, (2001) and Panisello and Quantick (2001) who reported on lack of motivation and illusion of food safety control due to low foodborne illness reporting as causes for lack of interest in establishing HACCP in food service establishments and other small scale industries. An audit score on food hygiene and safety management was conducted and whilst all the schools in Lincolnshire were in the excellent category, majority (75.5\%) of the schools from Ashanti Region were in medium hygiene category. Thus in the absence of established and operational FSMS, hygiene practices and food safety management become under standardized, with kitchen staff basing their food safety success on experience and luck (Taylor, 2001).

\subsection{Management commitment to kitchen staff training in Lincolnshire and Ashanti Region}

With the exception of food hygiene training which is a legal requirement, kitchen staff are required to receive on job instruction/training to ensure smooth operation. These may include health and safety, process control, new products development, new equipment usage, work instructions and records keeping, training reinforcement and other related on-job information including changes in legislation related to the products as and when they happen. Chapter XII of Regulation (EC) No 852/2004 (European Union, 2004) on training requires food business operators to ensure staff are given adequate training that commensurate with their work activity. Formal education, private training groups and work place training were dominant training providers in Lincolnshire whilst Government agency was also present in Ashanti Region (Table 5).

Training was however underutilised in Ghana as $87 \%$ of kitchen staff from Ashanti Region schools did not have any training providers. Staff job training on site was predominantly what was given during induction as reported by $69 \%$ of staff in Ashanti Region whilst 26\% had never had on-job training. The 2012 Public Health Act 851 Section 106 (Food and Drugs Authority, 2012) and the 1992 Food and Drugs Law of Ghana (Food and Drugs Authority, 1992) Section 6 on Manufacture of food under supervision, requires persons with appropriate knowledge and qualification to be in supervisory position in approved food premises to ensure food safety. Matrons apparently did not operate by this rule probably due to the lack of detailed written information under this provision as compared to other sections of the Act. In Lincolnshire 58\% of staff received on job training each year. Another 25\% had had on job training but was more than a year. Only $8 \%$ had received no on job 
Table 4

Food hygiene requirements and kitchen matrons/managers in schools reported in percentages.

\begin{tabular}{|c|c|c|c|}
\hline Variables & Lincolnshire & Ashanti region & Chi square \\
\hline \multicolumn{4}{|l|}{ Matrons Gender } \\
\hline Male & 1.82 & 0.00 & \\
\hline Female & 16.36 & 81.82 & \\
\hline \multicolumn{4}{|l|}{ Matron's level of education } \\
\hline Secondary school & 7.27 & 21.82 & $10.921(0.052)$ \\
\hline HND & 5.45 & 20.00 & \\
\hline First degree & 3.64 & 5.45 & \\
\hline City and Guilds & 0.00 & 30.91 & \\
\hline FSM level 3 & 1.82 & 0.00 & \\
\hline No response & 0.00 & 3.64 & \\
\hline \multicolumn{4}{|l|}{ Matron has hygiene qualification } \\
\hline Yes & 18.18 & 56.36 & $4.173(0.041)$ \\
\hline No & 0.00 & 25.45 & \\
\hline \multicolumn{4}{|l|}{ Matron's Years of work experience } \\
\hline $1-5$ & 1.82 & 14.55 & $19.715(0.001)$ \\
\hline $6-10$ & 1.82 & 12.73 & \\
\hline $11-15$ & 1.82 & 7.27 & \\
\hline $16-20$ & 9.09 & 1.82 & \\
\hline$>20$ & 3.64 & 45.45 & \\
\hline \multicolumn{4}{|c|}{ Current number of Kitchen staff manned } \\
\hline $1-10$ & 12.73 & 5.45 & $26.787(0.001)$ \\
\hline $11-20$ & 5.45 & 12.73 & \\
\hline $21-40$ & 0.00 & 30.91 & \\
\hline $31-40$ & 0.00 & 21.82 & \\
\hline$>40$ & 0.00 & 10.91 & \\
\hline \multicolumn{4}{|l|}{ Do you have FSMS } \\
\hline Yes & 18.18 & 0.00 & $55.000(0.001)$ \\
\hline No & 0.00 & 81.82 & \\
\hline \multicolumn{4}{|c|}{ Would you be interested to implement HACCP in your school } \\
\hline Yes & 0.00 & 70.91 & $55.000(0.001)$ \\
\hline No & 0.00 & 7.27 & \\
\hline HACCP already in place & 18.18 & 0.00 & \\
\hline Depends on school authorities & 0.00 & 3.64 & \\
\hline \multicolumn{4}{|l|}{ Food hygiene audit score } \\
\hline 9-10 (Excellent) & 18.18 & 0.00 & $55.000(0.001)$ \\
\hline $7-8.9$ (Good) & 0.00 & 14.45 & \\
\hline 5-6.9 (Medium) & 0.00 & 61.82 & \\
\hline $2-4.9$ (Poor) & 0.00 & 5.45 & \\
\hline
\end{tabular}

Data on 45 Matrons from Ashanti Region and 10 from Lincolnshire.

SFBB - safer food better business, HACCP - hazard analysis and critical control point, FSMS - food safety management system.

Table 5

Hygiene training Provision and culture in schools-kitchen staff responds reported in percentages.

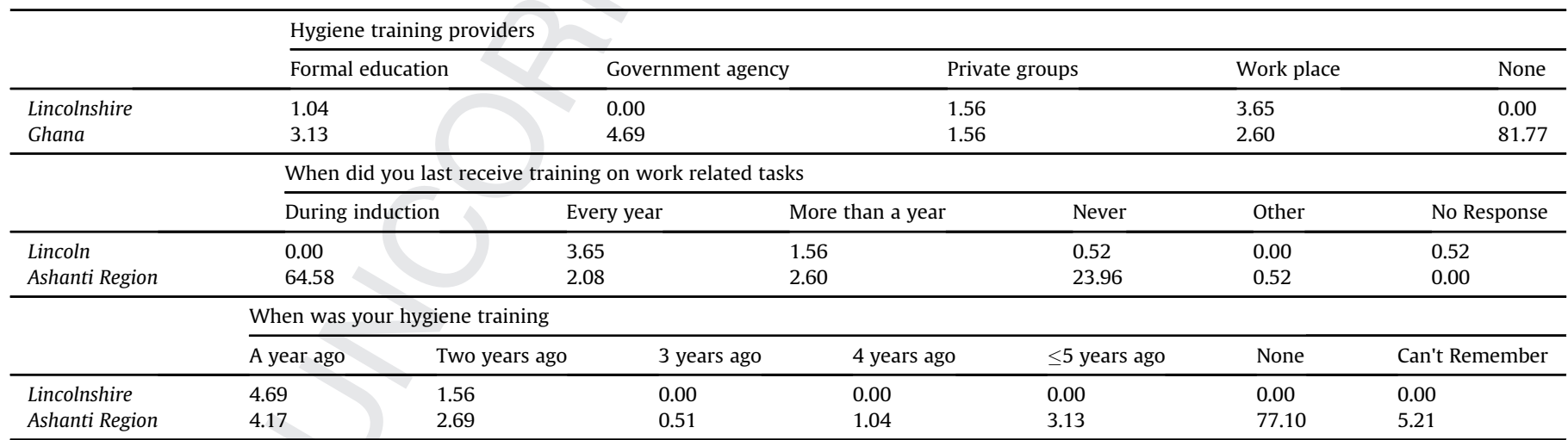

Data on 180 kitchen staff from Ashanti Region schools and 12 from Lincolnshire.

training. With hygiene training frequency, all staff from Lincolnshire reported of one to 2 years as the last period hygiene training was received. In Ghana, $82 \%$ of the 180 staff had never received hygiene training and of those who had received hygiene training the longest period since training was 5 years (3\%) and these were apparently those who had their training as part of their formal education. The 9\% from Ashanti who reported to have received some training ranged from 1 to 4 years. Thus both on job training and hygiene training were under practiced in Ashanti Region and this could have serious effects on student's food safety.

\section{Conclusion}

Although there are provisions in Food Laws in both the UK's 1990 Food Safety Act and Regulation (EC) No 852/2004 and the Ghanaian 2012 Public Health Act and the 1992 Food and Drugs Law, 
regarding good hygiene practices requirement in food service, school kitchen staff in Lincolnshire and Ashanti Region significantly differed in their compliance. Staff hygiene practices including hand washing, infectious disease reporting and management, wearing of jewellery during food preparation and eating during food preparation were substandard in the Ghanaian schools. Lack of food temperature monitoring devices and adequate hand washing facilities equally affected hygiene practices. Supervisors and staff in Ghana required training in Good Hygiene Practices and HACCP that commensurate with their roles. There was the need for Government agencies in charge of training to regularise and improve on this task. Absence of established food safety management systems in schools had motivational, management and legislative connotations that required attention in Ghana.

\section{Uncited reference}

Food Standards Authority, 2013.

\section{Acknowledgement}

The researcher would want to thank her Employer University of Education Winneba, Ghana, for funding this research and the Dean and staff of the National Centre for Food Manufacturing-University of Lincoln UK for their supervision and support. She equally acknowledges the Food Standard Agency UK for the audio-visuals on Safer Food Better Business for training of kitchen staff and last but not the least Hygiena International-UK for the donation of ProQ3 clean rapid protein food residue test kit for training purposes.

\section{References}

Ababio, P. F., Adi, D. D., \& Commey, V. (2013). Traceability: Availability and efficiency among food industries in Ghana. Food and Nutrition Science, 4, 131-135.

Ababio, P. F., \& Lovatt, P. (2015). A review of food safety and food hygiene studies in Ghana. Food Control, 47, 92-97.

Abelson, P., Forbes, P. M., \& Hall, G. (2006). The annual cost of food borne illnesses in Australia. Common Wealth of Australia, 1-108(2006). Available at: www.af.gove. au/cca accessed on $11 / 08 / 12$.

Afoakwa, O. A. (2005). Enhancing quality of feeding in educational institutions in Ghana-development and challenges. The global child nutrition forum 2005. Baltimore, Maryland USA http://works.bepress.com/emmanueloheneafoakwa/40 accessed on 13/02/2013.

Bhat, R. V., \& Waghray, K. (2000). Review of street foods in Africa. World Review Nutrition Dietetic, 86, 100-122.

Daniels, N. A., Mackinnon, L., Rowe, S. M., Bean, N. H., Griffin, P. M., \& Mead, P. (2002). Foodborne disease outbreaks in United States schools. The Pediatric Infectious Disease Journal, 21(7), 623-628.

Dwumfour-Asare, B. (2015). Effect of local authorities' field monitoring visits on awareness of regulation and hygiene practices among street food vendors: the case of two district capitals in Ghana. Journal of Behavioural Health, 4(3), 71-80.

European Union. (2004). Council Regulation 852/2004 of 29.4.04a on the hygiene of foodstuffs. Official Journal of the European Communities, L 139 (Brussels)

Food Standard Agency. (2011). Annual report of the chief scientist 2011/2012. Available at: www.fsa.gov.uk accessed on 11/18/12.

Food Standard Agency. (2014). New UK food poisoning figures published- refined real burden of disease estimates. Available at: www.food.gove.uk accessed on 05/04/2015.

Food Standards Agency. (2013). Food safety Act 1990 - UK. www.legislation.gov.uk.

Food Standards Authority. (2013). Personal communication with the documentation department in Ghana.

Food and Drugs Authority. (1992). The food and Drugs Act. PNDCL 3058 of 1992. www.fda.gov.gh.

Food and Drugs Authority. (2008). Contaminated food killed 90,692 in 2006. Available at www.modernghana.com accessed on 29/4/13.

Food and Drugs Authority. (2012). Public health Act 851. Food and Drugs Authority Ghana. www.fda.gov.gh.

Ghana Statistical Service. (2012). 2010 population and housing censors. Ghana Statistical service. Available at: www.gss.gov.gh accessed on 11/08/12.

Gupta, S. N., \& Gupta, N. (2009). Outbreak of gastroenteritis in tibetan transit school, Dharamshala, Himachal Pradesh, India. Indian Journal of Community Medicine, 34(2), 97-101.

Johnson, T. P., Tomlin, K. I., Oduro-Yeboah, C., Tortoe, C., \& Quayson, T. E. (2008). A case study to develop an appropriate quality assurance system for two cassava-based convenience foods in Ghana. Internet Journal of Food Safety, 10, 81-84.

Lee, B. (2013). Food Safety Interventions- A review of food safety interventions and evaluation in food service establishments. National Collaborating Centre for Environmental Health. British Columbia Centre for Disease Control.

Malm, K. L., Nyarko, K. M., Yawson, A. E., GOGO, B., Lawson, A., et al. (2015). Foodborne illness among school children in Ga East, Accra. Ghana Medical Journal, 49(2), 72-76.

Marzona, M. A., \& Balzaretti, C. M. (2013). Protecting child health by preventing school-related foodborne illnesses: microbiological risk assessment of hygiene practices, drinking water and ready-to-eat foods in Italian kindergartens and schools. Food Control, 34, 560-567.

Meldrum, R. J., Mannion, P. T., \& Garside, J. (2009). Microbiological quality of Readyto-Eat food served in schools in Wales, United Kingdom. Journal of Food Protection, 72(1), 197-201.

Ministry of Education. (2009). Representation on basic statistics and planning parameters for SHS in Ghana 2008/2009. Available at: www.ges.gov.gh accessed on $12 / 27 / 12$.

Ministry of Food and Agriculture/World Bank. (2007). Review of food safety in Ghana. Viewed 14/10/12 www worldbank org.

Ministry of Health Ghana. (2007). The Ghana Health Sector annual programme of work. Ministry of Health, 2007. viewed 6/12/2013 www.moh.gov.gh.

Office of National Statistics UK. (2013). Population estimates for UK, England, Wales, Scotland and Ireland, Mid-2013. Available at: www.ons.gov.uk accessed on 05/ $04 / 2015$

Panisello, P. J., \& Quantick, P. C. (2001). Technical barriers to hazard analysis and critical control point (HACCP). Food Control, 12, 165-173.

Panisello, P. J., Rooney, R., Quantick, P. C., \& Stanwell-Smith, R. (2000). Application of foodborne disease outbreak data in the development and maintenance of HACCP systems. International Journal of Food Microbiology., 59, 221-234.

Rheinlander, T., Bakang, M. O., Takyi, H., Konradsen, F., \& Samuelson, H. (2008). Keeping up appearances; perceptions of street food safety in urban Kumasi Ghana. Journal of Urban Health, 85(6), 952-964.

Rodriguez-Caturla, M. Y., Valero, A., Carrasco, E., Posada, G. D., Garcia-Gimeno, R. M., \& Zurera, G. (2012). Evaluation of hygiene practices and microbiological status ready-to-eat vegetable salads in Spanish school canteens. Journal of Science Food and Agriculture, 30(92), 11.

Santana, G. N., Almeida, C. C. R., Ferreira, J. S., \& Almeida, P. F. (2009). Microbiological quality and safety of meals served to children and adoption of good manufacturing practices in public school catering in Brazil. Food Control, 20 , 255-261.

Sneed, J., \& Henroid, D. (2007). Impact of educational interventions on hazard analysis and critical control point (HACCP) programme implementation in Iowa schools. Journal of Child Nutrition and Management, 1 Spring 2007.

Sumner, S., Brown, L. G., Frick, R., Stone, C., Carpenter, L. R., Bushnell, L., et al. (2011). Factors associated with food workers working while experiencing vomiting or diarrhoea. Journal of Food Protection, 74(2), 215-220.

Taylor. (2001). HACCP in small companies: benefit or burden. Food Control, 12(4), 217-222.

WHO. (2012). Manual for integrated foodborne disease surveillance in the WHO African Region. Brazzaville: WHO Regional Office for Africa, 2012.

WHO/FAO. (2009). Codex Alimentarius- food hygiene basic Text (4TH ed.). Rome: WHO/FAO, 2009.

World Bank. (2016). World development indicators. Available at: google.co.uk/ publicdata/explore accessed on 06/04/2016. 